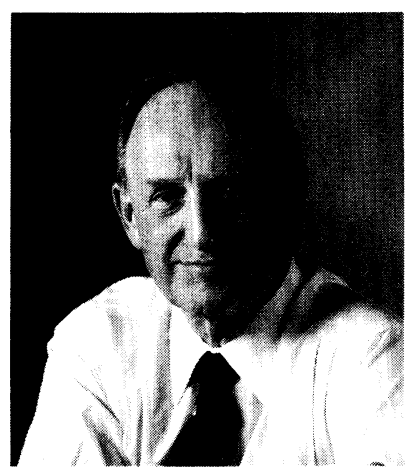

\section{Here We Go Again}

With this issue we start Volume 34 of Optical Engineeringmy fifth volume as your editor. Let me take the opportunity to thank all those involved with the journal and to wish staff, authors, reviewers, members, and other readers a very happy and prosperous 1995.

\section{Authors' Opinions}

Under the title "Optical Engineering Readers: We Got Your Input" we published the results from a reader questionnaire (see September and October 1994 editorials). We are now pleased to bring you the results of a survey of recent authors. We contacted 329 recent authors and received 80 responses.

Was OE your first choice as a journal in which to publish?

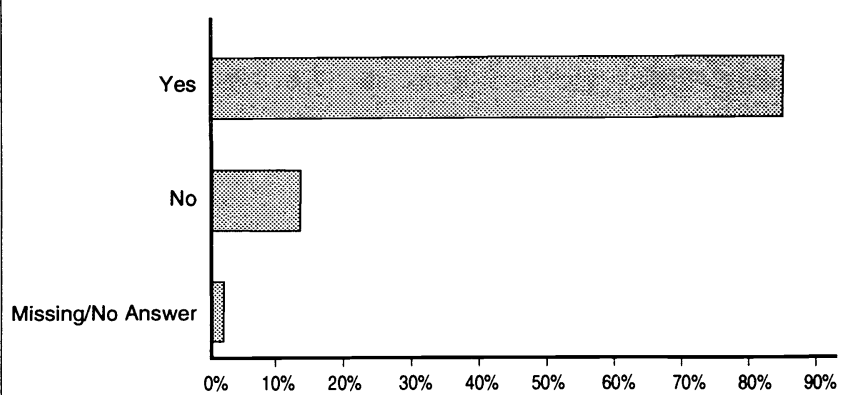

How many times do you refer to OE on a monthly basis?

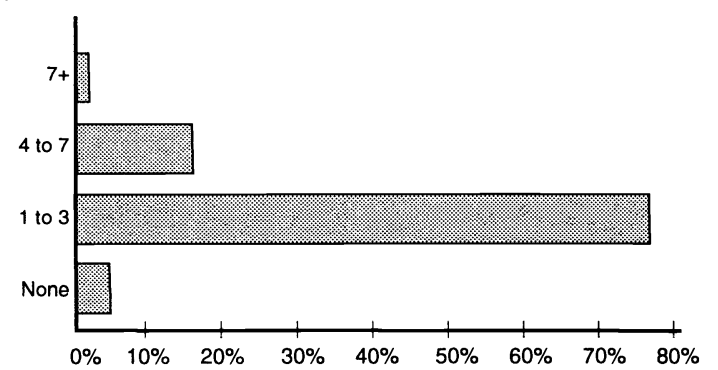

How often do you recommend $O E$ to a colleague for submission of a paper?

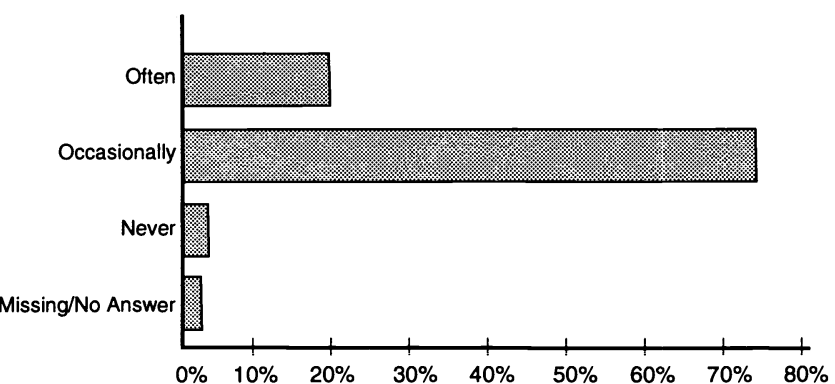

I am primarily interested in basic research/theory type papers.

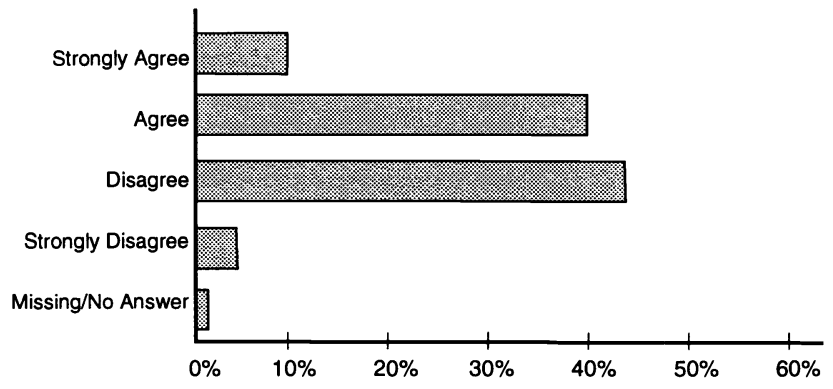

I am primarily interested in applications-oriented papers.

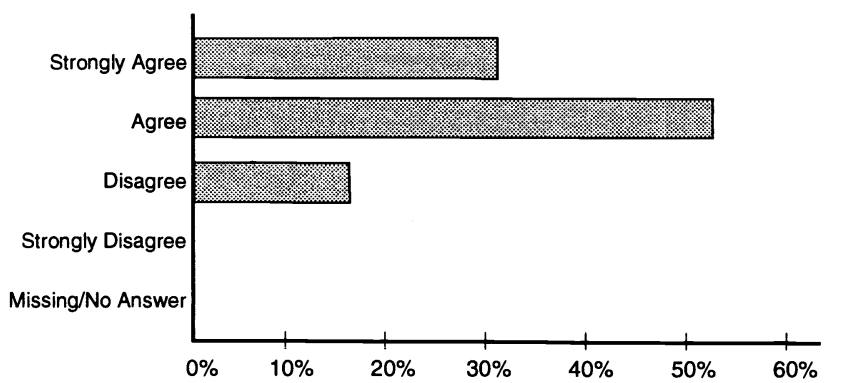


Which journals do you see as alternatives to OE in which to publish your work?

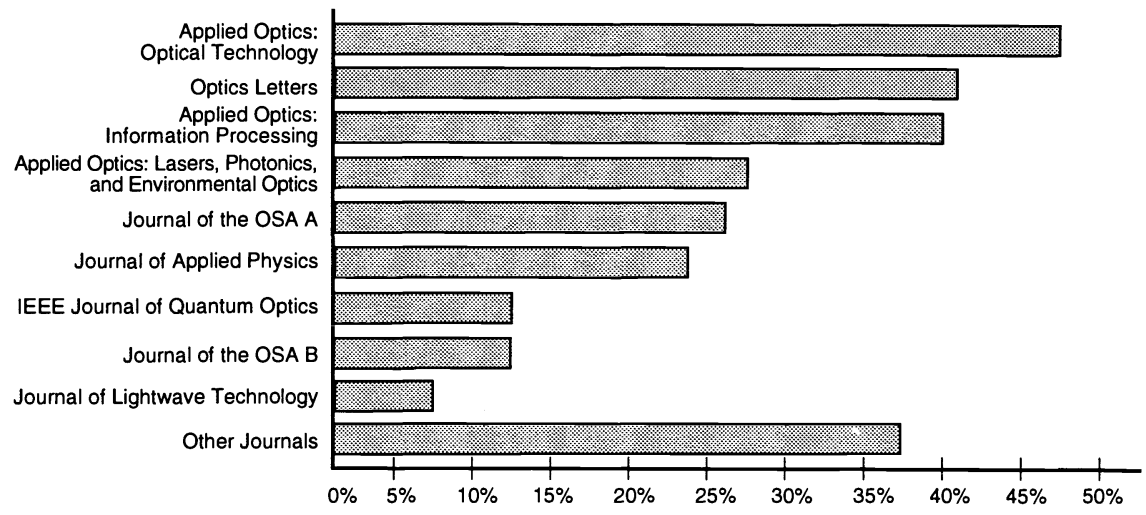

I consider OE:

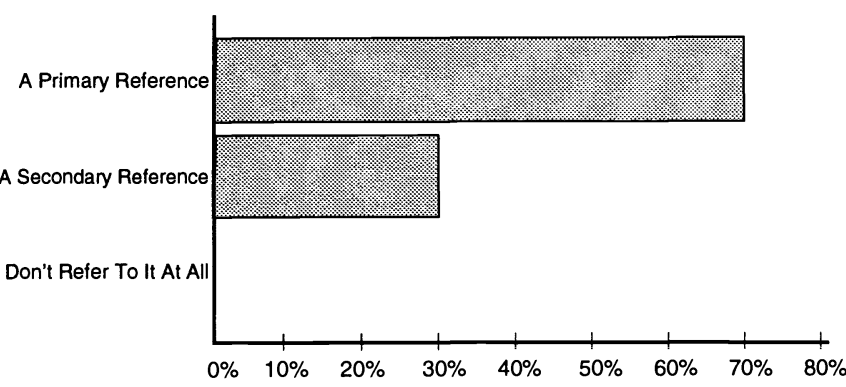

The review process was efficient.

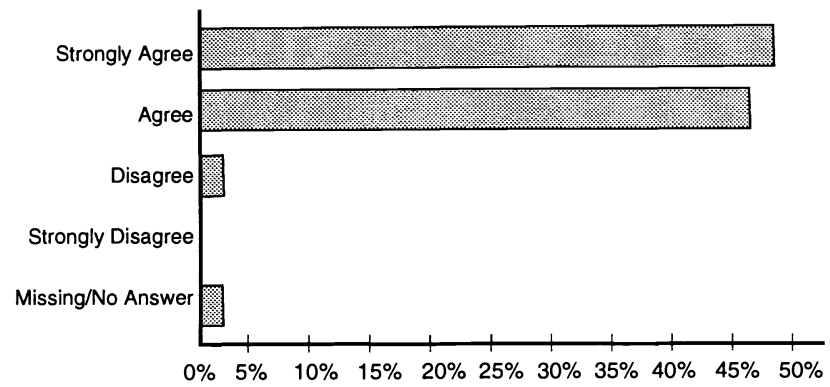

The review process was fast enough.

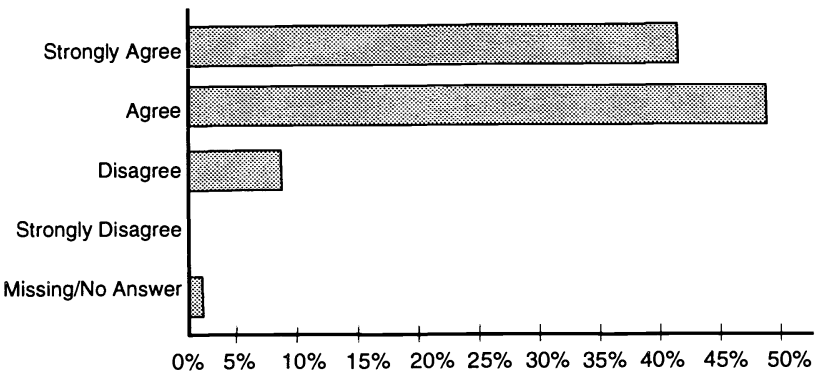

The editorial/production process was fast enough.

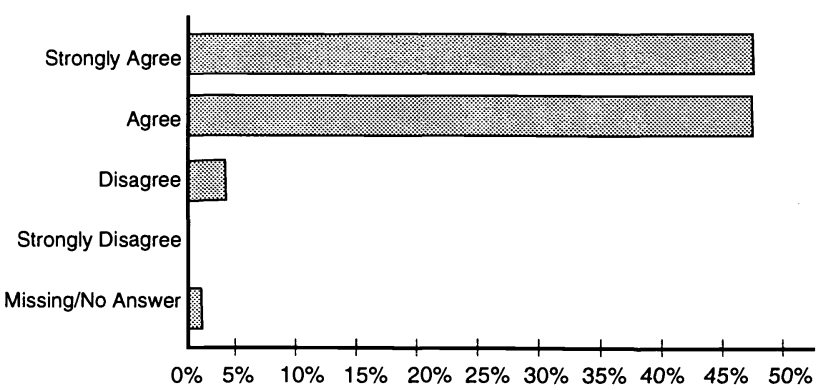

A six- to eight-month turnaround from acceptance of a paper to publication is acceptable.

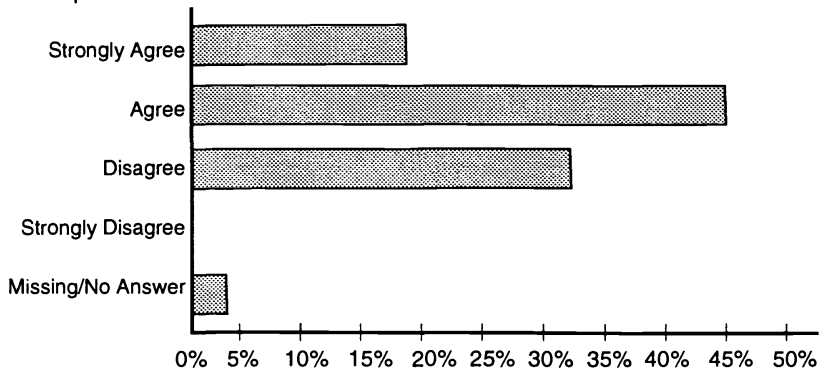

I have access to OE:

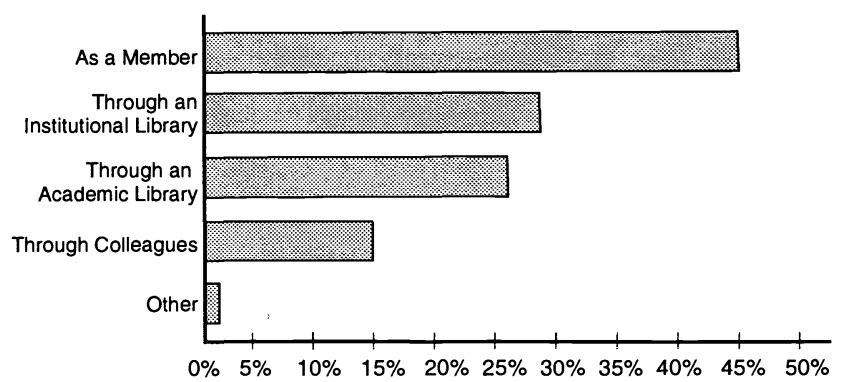

Brian J. Thompson

Editor 